International Journal of Agricultural

Science and Research (IJASR)

ISSN (P): 2250-0057; ISSN (E): 2321-0087

Vol. 11, Issue 1, Jun 2021, 11-20

(C) TJPRC Pvt. Ltd.

\title{
DESIGN AND IMPLEMENTATION OF ARDUINO BASED MILK QUALITY
}

\section{ANALYSER}

\section{SUMITRA GOSWAMI}

Teaching Associate, Engineering \& Technology Centre for Animal Sciences, Rajuvas, Bikaner, India

\section{ABSTRACT}

There is a dramatic increase in the production of milk in the present generation, which eventually increased the number of milk centres in different regions. This is because milk is the primary source of nutrition for infants, pregnant ladies as well as adults. The best quality milk has good density and free from adulterants. To maintain the income from milk and increase the yield few adulterants are added to milk. Because much of the milk comes from farmers, the likelihood of mistaking the details is very high where farmers do not understand it. These adulterants may affect the quality of milk. These days milk adulteration becomes the biggest social issue. Serious health issues occur from the consumption of adulterated milk. It is necessary to detect milk adulteration and ensure the quality of milk. The detection of milk adulteration can be performed using various types of sensors like pH sensors, gas sensors, temperature sensors. To make the method more cleared to all the people who deposit the milk, this implementation is built to make it more transparent. This system is based on Arduino Controller. This Arduino controls the whole milk analyser system. Various types of sensors are interfaced with controllers. This is a user-friendly system.

KEYWORDS: Arduino, pH Sensor, Gas Sensor, Bluetooth, Real Time Clock, Temperature Sensor, FAT Measurement, $L D R, L E D$

Received: Dec 14, 2020; Accepted: Jan 04, 2021; Published: Jan 22, 2021; Paper Id.: IJASRJUN20212

\section{INTRODUCTION}

Milk is a primary source of nutrition for humans. Milk contains numerous kinds of carbohydrates, fat, protein, vitamins, enzymes, and minerals. They will vary in line with the breed of cows, their feed, season, stage of lactation, and from several different factors. The connection between these milk constituents is stable and may be used for detection of any adulteration within the milk is occurred or not. India is the largest milk producer country. One of the national surveys in India has revealed that approx.68.4 \% of the milksamples examined did not meet the milk standard. That means approx. $70 \%$ of the milk Sold and consumed in India is adulterated milk, which contains adulterants like detergent, water, urea, starch, and many others adulterants. These adulterants affect the quality of milk and also decrease the nutritional value of milk. Therefore the quality of milk should be monitor at the dairy farm or by farmer itself using simple, reliable, hand held adulteration detecting system or machine, which can detect the $\mathrm{pH}, \mathrm{FAT}$, odour and other adulterant in milk.

Term 'Adulteration' means the addition of other substances to milk to increase the quantity of raw milk. Milk can be also adulterated during unhygienic processing, packaging, and distribution. Water is used as a most common adulterant, which increases the quantity of milk but decreases the quality of milk. Various atmospheric factors like temperature, humidity and darkness also affects the quality of milk. These can control by refrigeration and vacuum storage. 
Milk quality and hygiene is the major concern in India. The quality of Milk need to be analysed and it should be prevented from adulteration. There are various types of analytical techniques for detecting the milk adulteration is available. But these analytical techniques are expensive and time consuming. For analytical testing the knowledge of test is also necessary. This of Arduino Based Milk Quality Analyser system is design and implemented to provide low cost detection of milk adulteration, and also to ensure the quality of milk. This system is based on Arduino controller. This is low cost, simple and user friendly system. That can be used to check the adulteration at primary level.

\section{LITERATURE SURVEY}

In this research work microcontroller based system is developed for data monitoring and quality analysis of milk [1]. By using this important parameters of milk like $\mathrm{pH}, \mathrm{CLR}, \mathrm{FAT}$ and SNF are monitored. Butyrometer is used to detect the FAT percentage in milk. Lactometer is used to measure CLR value. By using the FAT percentage and CLR value the SNF value is obtained.

The paper defined the design and production work for the development of a low-cost sensing technique based on a radio-frequency excitation electromagnetic planar sensor. Computer-assisted computing enables online quality management to be quick [2].

In this research work IOT based system is developed [3]. In this system microbial activity is determined by gas sensor. In this system milk salinity is measured by salinity sensor, milk level is measured by level sensor. This system is also based on RFID. Customers have their own RFID card which maintains their milk dairies. Milk weight, Fat and CLR are measured by this system. This system is fast and accurate.

In this research work, they developed a Raspberry- Pi3 based system [4]. They replaced the software application by a web based application. They developed a wireless communication between mil automation system and server. They developed a milk automation machine using IoT and Data mining. This system minimizes the overall cost and enhances the efficiency.

This research work is based on Spectroscopy concept [5]. In this research work, they developed an automatic fat measuring system. This system is embedded technology based. This system used RFID techniques for Unique Identification for all milk depositors. This can store all information related to all milk depositor for future reference.

In this research, research designed a Milkotester for FAT and CLR measurement of Milk using Arduino Microcontroller [6]. They developed a low cost system which measure mil parameters like SNF (Solid but not FAT), FAT and CLR.

In this work, they developed a smart milk quality detections system [7]. This is low cost and efficient milk parameter measurement system which based on Arduino controller. This system measured the milk parameters like $\mathrm{pH}$, FAT, and SNF (Solid but nor Fat).

The researcher developed Arduino based system to capture the milk parameters [8]. This system detect the parameters of milk like quantity, $\mathrm{pH}, \mathrm{CLR}$ and SNF. This system uses Ultrasonic Sensor, pH Sensor and Lactometer to measure quantity, $\mathrm{pH}$ and CLR respectively. This system is low cost and efficient to detect adulteration of the milk.

In this review paper many techniques of milk testing are discussed. Milk parameters in milk detected using various types of sensor. Microbial activity can be detected using gas sensor, if milk is stored long time. Ultrasound 
techniques are mostly preferred for analysis of milk parameters [9].

This system is based on IoT (Internet of Thinking). In this system sensors are interfaced with Intel Galileo Gen II board. This Intel Galileo Gen II stored the results obtained from sensor on cloud. This stored data can be access by every user. $\log$ in is required to access these data [10].

This system is implemented using AVR Microcontroller [11]. In this system all sensors are combined ant form a compact system. Which analyse quality of milk in different parameters, and the result is displayed on LCD screen. Problems faced in dairies can be prevented using these types of milk testing system. This system is portable and easy to use.

\section{PROJECT METHODOLOGY}

In this research, presenting the Arduino based milk quality and quantity estimation. In this proposed system customer can access milk parameters data using their mobile through Bluetooth. Data can be stored in their mobile memory as a Milk Log using android mobile application like serial Bluetooth terminal. Real time clock module is used for capture real time milk parameters like $\mathrm{pH}$, Temperature, Salinity, and other milk adulteration.

This system analyses the milk quality by detecting the amount and types of adulterants added in milk. The adulterants are detected by use of electronic devices interfaced with various types of sensors.

Mainly quality of milk is captured by $\mathrm{pH}$ level of milk which is measured by $\mathrm{pH}$ sensor.

Gas sensor is used to detect the odour of milk. When milk is stored for long time, microbial activities started in milk which change the smell of mil, that can be detect by gas sensor.

\section{MAIN COMPONENTS OF THIS SYSTEM}

Following are the main components of this proposed system

Arduino Uno: In this proposed system UNO variant is used. Arduino Uno is a microcontroller. It is an open source electronics platform board, which is combination of both hardware and software. It can be pre-programmed directly using USB.

It is based on ATmega328P. It has digital I/P and O/P pins, Analogue I/P pins, $16 \mathrm{MHz}$ ceramic resonator, USB connection, power jack and reset button. It can be easily interfaced with other electronics modules and sensor. Its operating voltage is 5 Volt DC. It is low cost microcontroller board, which controls whole system and give faster and accurate result.

Power Supply Module: This power supply module is used to provide 5 volt de power supply to the Arduino controller. There is rectifier circuit with step- down transformer.

pH Sensor: $\mathrm{pH}$ is measuring hydrogen ion concentration in water or liquid. $\mathrm{pH}$ is a numeric scale which is used to measure the acidity or basicity of and liquid.

$\mathrm{pH}=-\log \left[\mathrm{H}^{+}\right]$

Every liquid has its own $\mathrm{pH}$ according to their parameters. The $\mathrm{pH}$ of pure milk ranges from 6.7 to 6.9. It can be depending on breed of cattle and there lactation stage, their feed. Milk $\mathrm{pH}$ is changes over time or it change when adulteration occurred with milk. Milk pH detected using $\mathrm{pH}$ sensor. 
Milk with above and below this $\mathrm{pH}$ ranges is considered as abnormal milk. Consumption of this abnormal milk causes several health issues.

Temperature Sensor: Temperature is measured using thermometer. Milk has own temperature criteria. That temperature criteria should maintains during storage of milk for long time. Normally milk is safe at the temperature range of 35 to $40{ }^{\circ} \mathrm{F}$. Even when any other material or water mixed in milk the temperature of milk will be changed from its normal temperature range. Bacteria formation occurred when milk in above or below this normal temperature range and thus it not good for consumption. Variation in milk temperature is measured using temperature sensor.

Gas Sensor: Odour of milk is varying from fresh milk to adulterated milk. If the adulteration and toxicity in milk is high then it produces toxic gases, when the milk is preserved for very long time with the help of any external contamination. This preserved milk produces gas in the form of bad odour. This milk causesvarious types of health issue. It is not fir for consumption. For detecting these toxic gases in the form of bad odour are measured by Gas sensor or Air Quality Sensor (MQ135).

MQ135 gas sensor is used as a gas sensor. $\mathrm{SnO} 2$ is the sensitive material in this sensor. In clean air this material have low conductivity, when gas concentration is raising the conductivity of this sensitive material is rise. This sensor is highly sensitive to ammonia, sulphide and also sensitive to smoke and other harmful gases. It is low cost gas sensor. This sensor can be also used as domestic air pollution detector, Portable air pollution detector and Industrial air pollution detector.

LDR (Light Dependent Register): LDR (Light Dependent Register). It has a variable register, which depends on light. Resistance of LDR is increase when light intensity is decrease and resistance is decrease when intensity increases. Resistance of LDR is inversely proportional to intensity of light. LDR can be used in Automatic Security Light.

LCD Display: Liquid Crystal Display (LCD)is a flat - panel optical devices LCD display is used for displaying the various parameters of milk, or displaying the output of this system.

Bluetooth Module: Bluetooth module is interfaced with Arduino Controller. Bluetooth is used for access the real time data of this system. It can be accessed by each customers and milk depositors using their own mobile devices and also then can store data $\log$ in their own mobile device for further use using android mobile device.

\section{WORKING}

This system can be installed in a local dairy or milk vendor where farmers deposit milk. This system can be used as a primary milk analyser.

Once this device is properly installed and it's powered on with 5 volt de supply using power supply module. It starts reading from the various sensors interfaced with this Arduino Controller. The $\mathrm{pH}$ sensor detects the $\mathrm{pH}$ of milk sample. The normal milk pH is 6.5 to 6.8 . This gas sensor is detect any microbial activity occurs in milk or it measure the toxic gas coming from milk sample. Temperature sensor measure the temperature of milk and FAT measurement is done by light scattering principle. LED is used for emitting beam of light and LDRis used to measurement of scattering of beam of light. For this FAT measurement module there is closed box in which LED and LDR are install, high intensity LED is used in this system, when milk sample test tube placed between LED and LDR, Light beam (Emitted from LED) will passes through test tube of sample milk.Milk have tendency to scattered the light beam, when light beam passes through 
the milk sample. Light is scattered from milk sample, this light scattered from the milk sample collected by Light Dependent Register. Resistance of LDR is changes according to the light scattered from the milk sample, and measured data will be send to controller board. If there are more fat content in the milk. The amount of light scattered by the sample is high. The change in resistance of LDR is inversely proportional to the light scattered from Milk. Block diagram and working model of proposed system is showing in [APPENDIX-1.1] and [APPENDIX-1.2] respectively.

The range of Fat content in different cattle

For Cow milk fat -3.0 to 4.0per cent

For Buffalo - 7-8 per cents

Arduino controls the working of whole system. This system is pre-calibrated using standards with known values of different - different parameters of milk. The standard of all parameters can be different for different- different cattle, when all parameters are in normal range then the Green LED blink. It indicates that the particular milk sample is fresh or pure milk without any toxicity.

If the sample parameters are below or above the standard values then the RED LED start blinking. It indicates that the particular milk sample is adulterated or it may be toxic or not fit for consumption. Sample data can be access by mobile device through Bluetooth module, Bluetooth module is interfaced with this Controller. Real Time Clock module creates the real date and time log for each and every sample. The data log is stored in memory card. And each and every customer can store these log data in their mobile device through Bluetooth. Observation table of milk analyser is showing in [APPENDIX-1.3]

\section{CONCLUSIONS}

In this research work, we have developed anArduino based system which measures the quality of milk and give faster and accurate result then previous developed milk quality analyser system. This system can be used at dairy booth as a primary milk quality analyser for all milk depositors. Or customer can check quality analyser data using mobile device through Bluetooth. Bluetooth module is interfaced with Arduino Controller. Dairy vendor can maintains the milk analysing data of whole month. Real clock device also interfaced to store real time data of milk parameters which measured by various sensors. And each customer can check milk parameters of that particular dairy where this system is installed. This system is easy to use and gives accurate data. This is a reliable and low cost system. As a future work we can extend this system using Data Base Management System. Where all data related to milk depositors and customers is recorded in SQL. And that data is further used for billing on monthly basis.

\section{REFERENCES}

1. Neeraj Khera, Akash Kumar, Fajr Fajr, Taznoon Nisar Khajwal, (2019) "Microcontroller Based Parametric Data Monitoring and Quality Analysis of Milk" International Conference on Issues and Challenges in Intelligent Computing Techniques (ICICT), IEEE 27-28 Sept.

2. S. C. Mukhopadhyay, C. P. Gooneratne, S. Demidenko and G. S. Gupta, (2005) "Low Cost Sensing System for Dairy Products Quality Monitoring," 2005 IEEE Instrumentation and Measurement Technology Conference Proceedings, Ottawa, Ont., 2005, pp. 244-249, doi: 10.1109/IMTC.2005.1604109. 
3. Dr.G. Rajakumar, Dr. T. Ananth Kumar, Dr. T. S Arun Samual, Dr. E. Muthu Kumaran, (2018) "IoT Based Milk Monitoring System For Detection of Milk Adulteration”, International Journal of Pure and Applied Mathematics, Volume 118 No. 9, 2132.

4. Pravnav Thanedar, Shubham Pol, Akshay Shinde, Apura Mayekar, Sagar Shinde, (2018) "Enhanced Automation of Milk Analyser Using Internet of Things (IoT) and Data Mining” International Journal of Interdisciplinary Innovative Research \& Development (IJIIRD) Vol, 03 Issue 01.

5. M Sujatha, P. Nagarjuna, A. Bala Sai Ram, A. Hemanth Venkata Sai, K. Tarun, Sk Hasane Ahammad, (2019) "Visible Spectroscopy Analysis of Fat Content in Milk using Lab View”, International Journal of Recent Technology and Engineering (IJRTE) Volume 7 Issue 5S4, February.

6. Abhishek M. Aware, Ujawala A. Kshirsagar (Belorkar), (2017) "Design of Milkotester for Fat and CLR Measurement using Arduino Microcontroller", International Advanced Research Journal in Science, Engineering and Technology, Vol. 4, Issue 5

7. Mahale Santosh, Deshmukh Shital, Nakhate Anjali, Ambure Aishwarya, Chavan Kaveri, (2018) "Smart Milk Quality Detection System", International Journal for Research in Engineering Application \& Management (IJREAM) Special Issue- ICRTET

8. Y.R. Bhamre, M. B. Matsagar, C. G. Bighavkar, (2016) "Quantitive and Qualitative Analysis of Milk Parameters using Arduino Controller", International Journal of Advanced Research in Computer and Communication Engineering Vol. 5, Issue 8, August 2016

9. Raosaheb Chavan, Prof. Ulhas V. Patil, (2019) "Comprehensive Assessment of Various Milk Parameters Using Embedded and IoT Based Systems", IJSART - Volume 5 Issue.

10. Abhishek M. Aware, Ujwala A. Kshirsagar (Belorkar), (2017) "Design of Milk Analysis System for Dairy Farmers Using Embedded System", International Journal of Innovative Research in Electrical, Electronics, Instrumentation and Control Engineering Vil. 5, Issue 5

11. Prof. Dipti S. Bhade, Shradha J. Dobariya, Sanchita S. Landge, Prachi D. Babhale, Veebha M Atmande, (2019) “Implementation of IoT based Milk Quality Analyser using AVR Microcontroller", JETIR Volume 6, Issue 5

12. Anish Unnikrishnan M., Anoop Ravindran, (2015) "Electro-Milktestera Novel Method for Analysis of Milk Quality" International Journal for Innovative Research in Science \& Technology, Volume 2, Issue 04, pp-103-108.

13. BrownJ.V., RanjithH.M.P., and PrenticeG.A., (2018) “Comparative shelf-livesof skimmed, semi- skimmed and whole milks," International Journal of Dairy Technology, vol. 37, no. 4, pp. 2-5.

14. Yadav S.N., Kulkarni V.A., Gholap S.G., (2012) "Design of Milk embedded system for dairy farmers”, International Journal electronics and communication engineering and technology, Volume 3, Issue 2, pp.497-500.

15. BoreckiM, SzmidtM, Paw M. K.,BebM.,NiemiecT.,andWrzosekP., (2017)“Amethod for testing the quality of milkusing optical capillaries, "vol. 1, no. 1, pp. 37-39.

16. Prof.A.S.Mali, Aruna A.Chougale, (2015) "Low Budget System for Measurement of Milk Parameters and Billing for Dairy”, SSRG International Journal of Electronics and Communication Engineering (SSRG-IJECE) -Volume2Issue5, pp.108- 109.

17. BrennanD., AldermanD., SattlerL., ConnorbB., MathunaaC., (2013)Issues in development of NIR microspectrometer system for on-line process monitoring of milk product, Measurement, vol. 33, pp. 67-74,2013. 


\section{APPENDIX-1.1}

Block Diagram of Proposed System

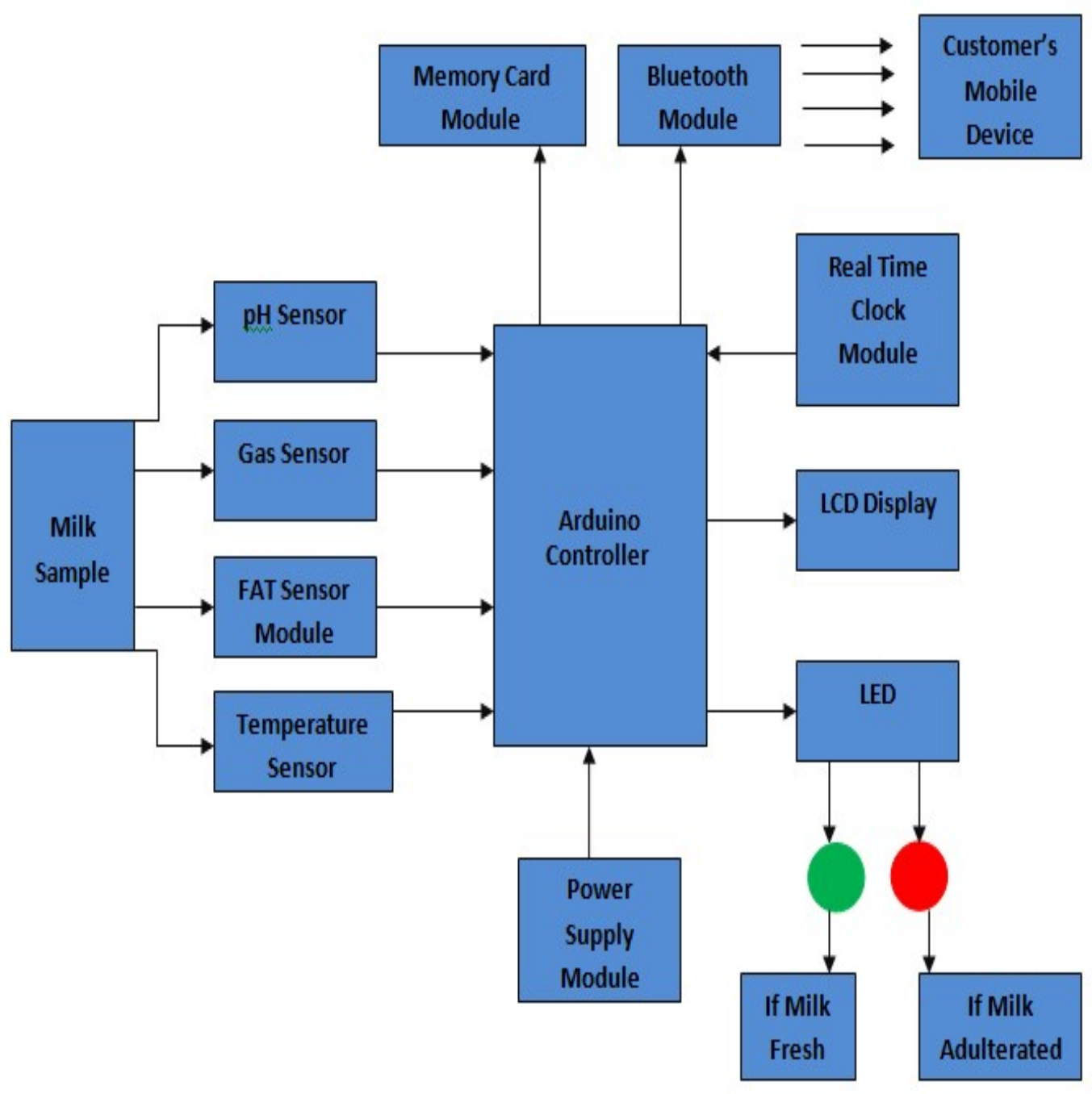




\section{APPENDIX-1.2}

Working model of Proposed System

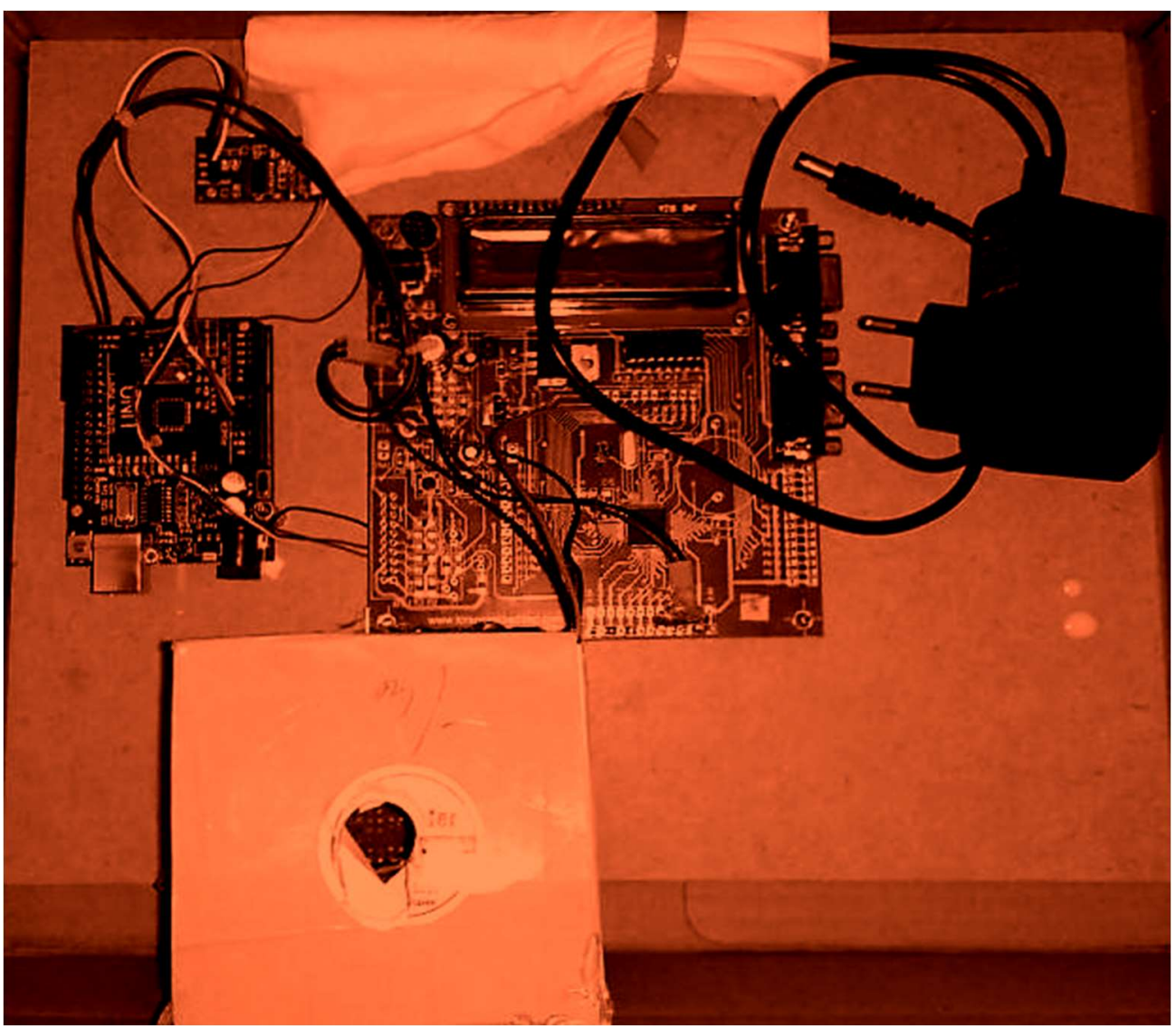

\section{APPENDIX-1.3}

Observation table of Milk Analyser system

\begin{tabular}{|l|l|l|l|l|l|}
\hline \multicolumn{1}{|c|}{ Samples } & \multicolumn{1}{c|}{ Fat } & \multicolumn{1}{c|}{ pH } & \multicolumn{1}{c|}{ Temperature } & \multicolumn{1}{c|}{ Odour } & \multicolumn{1}{c|}{ Quality } \\
\hline Pure milk & $3.2-3.5 \%$ & 6.8 (Normal) & 30.31 & $5 \%$ & High \\
\hline Water+milk & $0.5-2 \%$ & 6.4 (Normal) & 31.56 & $5 \%$ & Normal \\
\hline Milk+soap & $4-5 \%$ & 8.8 (Alkaline) & 32.43 & $11 \%$ & Low \\
\hline Milk+salt & $4-5 \%$ & 4.5 (Acidic) & 31.38 & $10 \%$ & Low \\
\hline
\end{tabular}

\section{REFERENCES}

1. ALGERIAN, RAW CAMEL MILK PRODUCTION IN, and S. SOUTH EASTERN ARID AREAS. "CONSTRAINT RELATED TO COLLECTION, STORAGE AND TRANSPORT: IMPACT ON PRODUCT QUALITY." International Journal of Applied and Natural Sciences (IJANS) 5.6, Oct - Nov 2016; 59-68 
2. OFFIA OLUA, B. I., QC ELUWA, and C. ABUAJAH. "Incorporation of Papain into Ice Cream: Impact on Pawpaw (Carica Papaya) Ice Cream Quality." IASET: International Journal of Biology, Biotechnology and Food Science (IASET: IJBBFS) 1.1: 7-22.

3. Magotra, Ankit, Anika Malik, and B. L Pander. "Candidate Genetic Markers Associated with Thermo-Tolerance in Animals." International Journal of Applied and Natural Sciences (IJANS) 6.6 (2017): 61-72.

4. KUMAR, PAVNESH, and MANISHA KUMARI. "TRANSFORMING RURAL LIFE: A CASE OF BAPUDHAM MILK PRODUCER COMPANY MOTIHARI." International Journal of Sales \& Marketing Management Research and Development (IJSMMRD) 9.2, Dec 2019, 45-56

5. SINGH, AWADHESH KUMAR, et al. "Constraints faced by the dairy farmers in adopting good farming practices in Uttar Pradesh." International Journal of Agricultural Science and Research 7.4 (2017): 123-130. 

